\title{
Cultivo primario de células ciliadas de adenoides humanos. Un modelo experimental para evaluar la actividad ciliar in vitro
}

\author{
Primary culture of human adenoid ciliated cells. \\ An experimental model to evaluate ciliar activity in vitro
}

Claudia González¹, Trinidad Sánchez², Ximena Fonseca¹, Manuel Villalón².

\begin{abstract}
RESUMEN
Introducción: El clearance mucociliar normal es el mecanismo de defensa básico de las vías respiratorias. Sin embargo, los mecanismos de control ciliar aún se desconocen. Con el fin de entenderlo mejor, se han desarrollado diferentes técnicas de cultivo de células ciliadas.

Objetivos: Desarrollar un modelo experimental a partir de cultivos primarios de tejido adenoídeo y cornete medio. Caracterizar la respuesta a adenosin trifosfato (ATP), agonista conocido de la frecuencia de batido ciliar (FBC).

Material y método: Cultivos primarios a partir de explantes de epitelio adenoídeo y cornete medio humano. Medición de FBC, con técnica de microfotodensitometría, en condición basal y en respuesta a ATP a diferentes concentraciones.

Resultados: $L a F B C$ basal (promedio $(X) \pm$ desv. estándar $(D E)$ ) para los cultivos de cornete medio fue $11,9 \pm 1,5 \mathrm{~Hz}$ y para tejido adenoídeo fue 10,9 $\pm 1,9$ ( $p>0,05$ ). Se observó un aumento en la FBC en respuesta a ATP, dosis dependiente. No hubo diferencia significativa en la FBC basal ni en la respuesta a ATP entre cultivos de cornete medio y adenoides.

Conclusión: El cultivo primario de células ciliadas nasales a partir de explantes de adenoides, es un modelo experimental reproducible, en el que es posible observar actividad ciliar y una respuesta funcional concordante con lo descrito en la literatura.
\end{abstract}

Palabras clave: Batido ciliar, ATP, adenoides, cornete medio, células ciliadas.

\begin{abstract}
Introduction. Mucociliary clearance constitutes the main defense mechanism of the airway, but the mechanisms of ciliary control are still unknown. With the aim of a better understanding of this process, many ciliated cells culture techniques have been developed.

Aims. 1. To develop an experimental model based on primary cultures from adenoid and middle turbinate tissue. 2. To characterize in this model the response to ATP, a known agonist of ciliary beat frequency (CBF).
\end{abstract}

${ }^{1}$ Médicos Otorrinolaringólogos. Hospital Clínico Universidad Católica de Chile.

${ }^{2}$ Departamento de Fisiología. Facultad de Ciencias Biológicas. Pontificia Universidad Católica de Chile. 
Material and Method. Primary cultures derived from human adenoid tissue and middle turbinate epithelial explants were obtained. CFB was measured by microphotodensitometry, both in basal conditions and in response to ATP at different concentrations.

Results. Basal CFB (average $(X)+$ - standard deviation $(S D)$ ) for middle turbinate cultures was $11.9+-1.5 \mathrm{~Hz}$, and for adenoid tissue was $10.9+-1.9 \mathrm{~Hz}(p<0.05)$. A CBF increase was observed in response to ATP, in a dose-dependent manner. No significant difference in basal CFB or in response to ATP was found between middle turbinate and adenoid cultures.

Conclusion. Primary culture of nasal ciliated cells derived from adenoid explants is a reproducible experimental model, in which it is possible to observe both ciliary activity and a functional response in accordance to what has been reported in the literature.

Key words. Ciliary beat, ATP, adenoid, middle turbinate, ciliated cells.

\section{INTRODUCCIÓN}

La mucosa de la cavidad nasal, al igual que el resto de la vía aérea, se encuentra cubierta por un epitelio cilíndrico ciliado pseudoestratificado. Cada célula ciliada está cubierta por 50 a 100 cilios en su cara apical. El movimiento permanente y sincrónico de estos cilios es uno de los factores primordiales en la mantención del clearance mucociliar, con el subsiguiente desplazamiento de polvo, bacterias y otros elementos hacia la faringe. Este es el mecanismo básico de defensa de las vías respiratorias ${ }^{1,2}$.

Para el estudio del movimiento y función ciliar se han diseñado diversos modelos, siendo uno muy utilizado, el cultivo primario de células ciliadas de vía aérea3,4. En estos cultivos ha sido posible estudiar el efecto de diversas sustancias sobre la frecuencia de batido ciliar (leucotrienos ${ }^{5}$, prostaglandinas ${ }^{6}$, endotelinas ${ }^{7}$; drogas, como salmeterol, salbutamol ${ }^{8}$, atropina ${ }^{9}$, eritromicina ${ }^{10}$, etc...). Los cultivos pueden ser obtenidos de mucosa nasal, traqueal, adenoides 0 de pólipos nasales.

En la vía aérea, el adenosin trifosfato (ATP) tiene un importante rol como mediador de una serie de funciones normales de la célula. Es liberado en forma autocrina y paracrina en el epitelio respiratorio y tiene un efecto estimulador (agonista) de la frecuencia de batido ciliar (FBC). Esta respuesta ha sido bien caracterizada en epitelio de tráquea de conejo ${ }^{11}$, oviducto de rata $^{12}$, tráquea ${ }^{13}$ y mucosa nasal humana ${ }^{14}$. La utilidad de los explantes de tejido adenoídeo para el estudio de actividad ciliar ya ha sido publicada por diversos autores ${ }^{15-17}$. Sin embargo, la respuesta a ATP no ha sido caracterizada en este modelo.
Hasta el inicio de nuestra investigación, ninguna de estas técnicas de estudio de mucosa respiratoria había sido puestas en práctica en otorrinolaringología en nuestro país. Motivados por este hecho, y con el fin de entender mejor el funcionamiento ciliar normal planteamos como hipótesis que los cultivos primarios de explantes de células ciliadas son un modelo experimental fácil de reproducir y que aquellos obtenidos a partir de tejido adenoideo tienen características similares a los obtenidos de mucosa nasal.

Los objetivos del siguiente trabajo son:

1. Desarrollar un modelo experimental a partir de tejido adenoídeo o de cornete medio, para el estudio de los mecanismos de control de la actividad ciliar in vitro.

2. Caracterizar y comparar la respuesta a ATP, agonista conocido de la frecuencia de batido ciliar (FBC), en cultivos primarios de explantes de tejido adenoídeo y de cornete medio.

\section{MATERIAL Y MÉTODO}

\section{Obtención de muestras}

Entre noviembre 2002 y octubre 2003 se tomaron muestras de cornete medio de pacientes sometidos a rinoseptoplastía, dacriocistorrinostomía y cirugía endoscópica de cavidades perinasales y muestras de adenoides de pacientes sometidos a adenoidectomía por hipertrofia adenoídea, previo consentimiento informado.

Las muestras fueron depositadas en un frasco con suero fisiológico 0,9\% y luego en un frasco con $5 \mathrm{ml}$ de solución Hank's suplementado con 
anfotericina B 0,125ug/ml, estreptomicina $10 \mathrm{ug} /$ $\mathrm{ml}$ y penicilina $\mathrm{G} 100 \mathrm{U} / \mathrm{ml}$.

\section{Cultivos primarios}

Los cultivos primarios se realizaron con el método introducido por Verdugo y cols ${ }^{18}$, que permite obtener monocapas confluentes de células epiteliales. Los adenoides son cortados en trozos de 2-4 mm, los que son lavados con una solución de Hank's estéril y se sumergen en medio NHS (NHS es el medio de Eagle modificado por Steinberger), cuya composición en milimolar (mM) es la siguiente: 137 $\mathrm{NaCl} ; \quad 5,09 \mathrm{KCl} ; \quad 1,14 \quad \mathrm{Na} 2 \mathrm{HPO} 4 \times 2 \mathrm{H} 2 \mathrm{O} ; 0,18$ KH2P04; 0,923 MgCl2x6H2O; 0,91 CaCl2x2H2O; 4,07 NaHCO3; 21,5 glucosa y 0,2 glutamina $(\mathrm{ph}=7,4)$. Además, este medio es suplementado con $1,0 \%$ de vitaminas, $1,0 \%$ de aminoácidos esenciales, $1,0 \%$ de aminoácidos no esenciales, $1,0 \%$ de piruvato y los antibióticos: neomicina $0,2 \mathrm{mg} / \mathrm{ml}$ y penicilina $0,12 \mathrm{mg} / \mathrm{ml}$. Los trocitos de epitelio, son depositados en cubreobjetos pretratados con gelatina al 0,1\%,y estos en cámaras de Rose. Los explantes son cubiertos con una membrana de diálisis, previamente esterilizada, y pretratada con medio de cultivo. Las cámaras de Rose se llenaron con $2 \mathrm{ml}$ de medio NHS que contiene $10 \%$ de suero de caballo inactivado por calor (ph 7,2-7,4) y se mantienen en una incubadora a $37^{\circ} \mathrm{C}$. El medio de las cámaras se renueva cada 48 horas. Después de aproximadamente 7 días en estas condiciones de cultivo se revisan diariamente los cultivos para determinar si han crecido nuevas células a partir de los explantes originales, formando una monocapa de células ciliadas que presentan batido ciliar sincronizado. Cuando la monocapa se ha formado, el cultivo se considera listo para estudio.

\section{Detección del batido ciliar con la técnica de microfotodensitometría}

La técnica consiste en el análisis de las fluctuaciones de luz que genera el movimiento de los cilios y que son detectadas por un fotodiódo asimétrico montado en el plano fotográfico del microscopio de fase ${ }^{19}$. La señal generada por las fluctuaciones de luz en el tiempo, es procesada por un analizador de espectros digital (Rapyd System), que entrega un espectro de la frecuencia de batido ciliar instantánea (Figura 1). El número de células o cilios a los que se les puede medir la frecuencia del batido en un determinado momento, está definido por la magnificación del microscopio y por el tamaño de la superficie activa del diodo de detección. El sistema que actualmente está montado en el laboratorio, permite la detección de la frecuencia en células ciliadas individuales que contienen aproximadamente 50-100 cilios por célula.

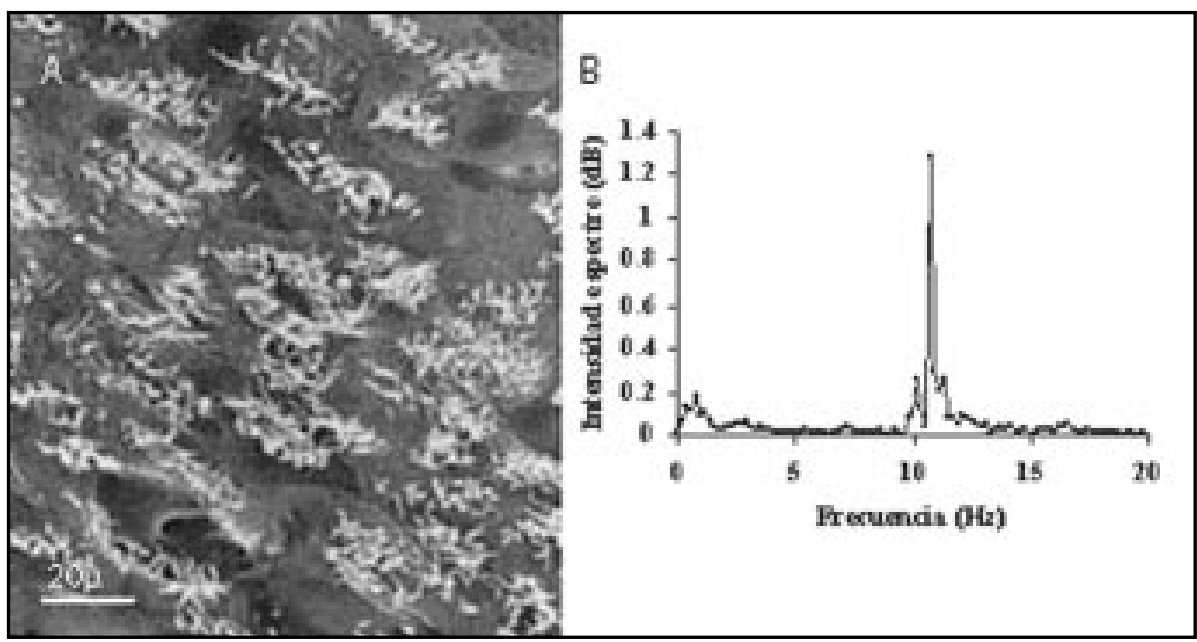

Figura 1: A. Microscopía electrónica de un cultivo de explante de adenoides. Es posible observar el penacho de cilios en algunas células y se reconocen claramente los límites celulares. B. Espectro de frecuencia de batido ciliar basal de una célula ciliada. La frecuencia de batido de la célula ciliada representada por este espectro corresponde a $11 \mathrm{~Hz}$. 


\section{Medición de frecuencia de batido ciliar}

Una vez que el cultivo primario alcanzó confluencia y actividad ciliar espontánea, cada uno de ellos se abre, se realizan lavados con solución Hank's y se mide la frecuencia de batido ciliar en el microscopio, el cual tiene una estufa con termostato para mantener la temperatura constante a $35^{\circ} \mathrm{C}$. Se realizaron mediciones de frecuencia de batido basal a varias células de un mismo cultivo, tratando de obtener una muestra lo más representativa posible de ese cultivo. Posteriormente se seleccionaron dos células con una frecuencia basal promedio para ese cultivo, con buena señal y se realizaron mediciones de FBC cada un minuto durante cinco minutos. Si la frecuencia permanece estable se agregó al cultivo ATP en concentración final de 1 micromolar $(\mu \mathrm{M}), 10 \mu \mathrm{M}, 50 \mu \mathrm{M}, 0100 \mu \mathrm{M}$ y se realizaron mediciones durante 25 minutos. Posterior a esto se lavó el medio con Hank's y se controló FBC por cinco minutos, para evaluar que la droga utilizada no haya alterado la función celular durante el experimento.

\section{Estadística}

El análisis estadístico se realizó con estadística descriptiva y test de student para diferencia de medias, utilizando Microsoft Excel 2000 y Prisma Graphpad.

\section{RESULTADOS}

\section{Cultivos primarios}

La técnica utilizada permitió obtener cultivos confluentes de células ciliadas con actividad ciliar espontánea. Durante el período descrito se obtuvo 40 cultivos viables, excluyendo los contaminados y aquellos en los que no se observó crecimiento de células ciliadas, 34 de ellos provenían de adenoides (21 pacientes) y 6 de cornete medio (4 pacientes).

Durante la obtención de la muestra un paciente presentó una epistaxis transitoria luego de la biopsia de cornete medio, que cedió con taponamiento nasal y oximetazolina tópica por algunos minutos, lo que retrasó el comienzo de la rinoplastía. No se registraron incidentes en relación a la obtención de muestras de adenoides.
Según el sitio de origen de la muestra, el promedio de días de incubación necesarios para observar células ciliadas con actividad espontánea fue $16 \pm 3,2$ días para cornete medio y 11, $25 \pm 2,01$ para adenoides $(p<0,05)$.

En todos los cultivos fue posible observar coexistencia de células ciliadas, células secretoras activas y otras células no identificadas de aspecto similar a fibroblastos. La Figura 1 muestra una microfotografía de microscopía electrónica de barrido de un cultivo, en la que es posible reconocer los límites celulares y el penacho de cilios ( 30 a 50) en el centro de la superficie celular.

Se registró la FBC basal en un total de 269 células, correspondientes a un total de 25 pacientes. Al evaluar la $\mathrm{FBC}$ en relación al número de días de cultivo, se observó que si bien existe una pequeña variabilidad en la FBC, ésta se mantiene en un rango promedio de 9,87 a 12,21 Hz, sin observar un deterioro estadísticamente significativo con el paso de los días de incubación de acuerdo a ANOVA (análisis de varianza) de una vía ( $p>0,05)$ Figura 2.

No se observó diferencia estadísticamente significativa en la FBC basal entre cultivos procedentes de adenoides 0 de cornete medio. La frecuencia basal fue de $11,9 \pm 1,5 \mathrm{~Hz}(X \pm D E)$ con un rango de 9,6 a $14 \mathrm{~Hz}$, para cornete medio y $10,77 \pm 1,9 \mathrm{~Hz}(\mathrm{X} \pm \mathrm{DE})$ con un rango de 6,5 a $17,5 \mathrm{~Hz}$. para adenoides $(p>0,05)$.

En cada cultivo fue posible observar células con distintas FBC basal, observándose una distribución normal de acuerdo al test Shapiro-Wilk, Figura 3. El $43,9 \%$ de las células tenía una FBC entre 8 y $10 \mathrm{~Hz}$.

\section{Incremento de FBC en respuesta a ATP}

El ATP en las concentraciones de $1 \mu \mathrm{m}, 10 \mu \mathrm{m}, 50 \mu \mathrm{m}$ y $100 \mu \mathrm{m}$, produjo un incremento rápido de la FBC, seguido de un plateau sobre la FBC basal, que luego del lavado con Hank's volvió a la FBC basal.

Se observó el efecto de diferentes concentraciones de ATP sobre la FBC, observándose un incremento del $28,7 \%$ en la FBC con ATP $10 \mu \mathrm{M}, 33 \%$ con ATP 50uM y 29,4\% con ATP 100uM. Figura 4.

Al comparar el efecto de ATP $1 \mu \mathrm{M}$ no se observó diferencias significativas entre el curso temporal ni las respuestas máximas de FBC entre cultivos de cornete medio y de adenoides. Figura 5. 


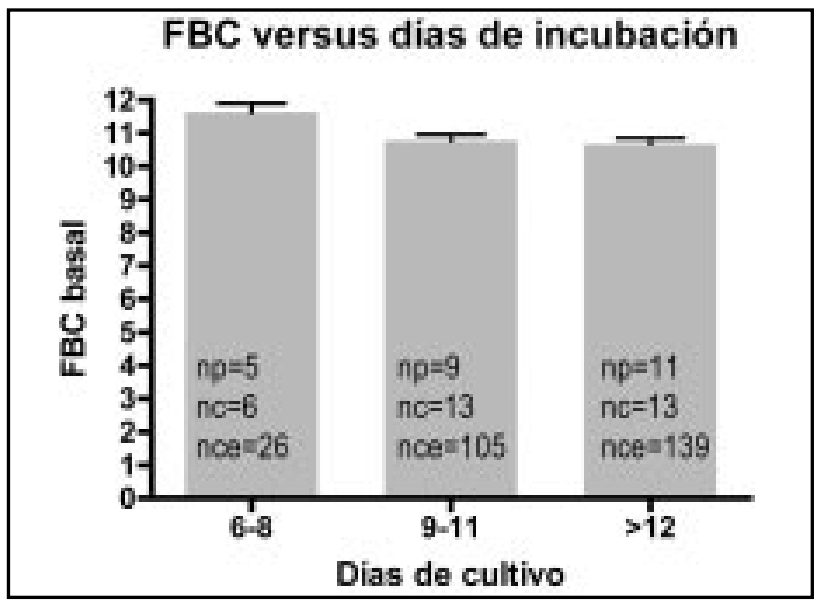

Figura 2: Frecuencia de batido ciliar promedio según días de incubación (np: número de pacientes, nc: número de cultivos, nce: número de células estudiadas).

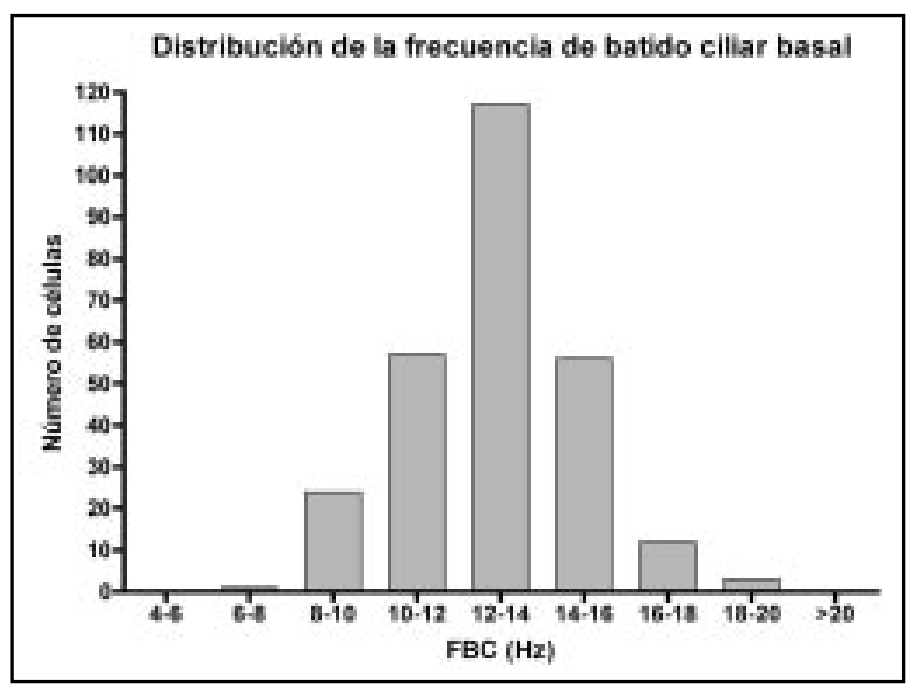

Figura 3: Distribución de las células ciliadas según la frecuencia de batido ciliar basal.

\section{DISCUSIÓN}

En este estudio observamos que los cultivos primarios de células ciliadas de vía respiratoria alta humana, son un modelo experimental reproducible, relativamente fácil de obtener. Además observamos que las células ciliadas responden a ATP y no hay diferencia entre cultivos procedentes de cornete medio y adenoides.

En los últimos años la investigación relacionada con las células ciliadas de la vía aérea ha descubierto el efecto que múltiples factores, ya sea físicos, am- bientales, químicos, neurotransmisores y otros, ejercen sobre el batido ciliar. La activación de los receptores purinérgicos por ATP produce un importante incremento en la frecuencia de batido ciliar en diferentes sistemas y especies de mamíferos ${ }^{8,20,21}$. Además el ATP puede ser degradado en la superficie celular a adenosina, por la acción de ectonucleotidasas. La adenosina se une a un receptor purinérgico A2BA y mediante la vía dependiente de adenosin monofosfato (AMP) cíclico genera un incremento en la FBC ${ }^{8}$. Sin embargo, aunque la respuesta a ATP y sus metabolitos parece ser importante en la vía aérea y ha 


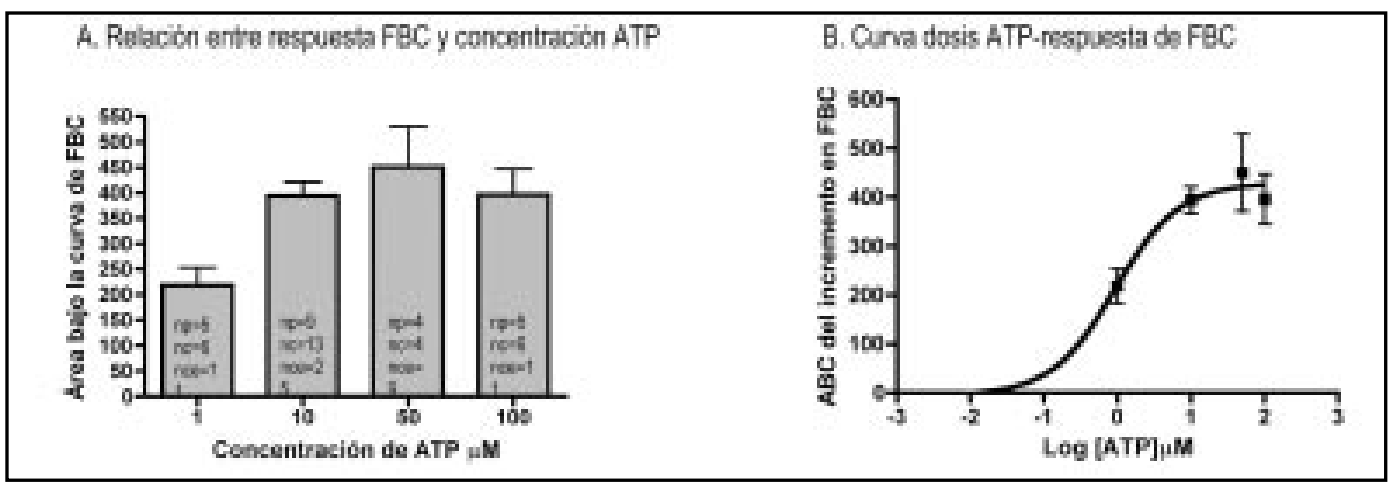

Figura 4: A. Relación entre FBC y concentración de ATP. El gráfico muestra el área bajo a curva (ABC) del incremento de la frecuencia de batido ciliar (FBC) en respuesta a distintas concentraciones de ATP. (np: número de pacientes, nc: número de cultivos, nce: número de células medidas). B. Curva dosis ATP-respuesta FBC. El gráfico representa la relación entre el aumento logarítmico de la concentración de ATP y el incremento de la FBC, expresada como ABC. La línea continua representa el ajuste sigmoideo de los datos $\left(\mathrm{R}^{2}=0,962\right)$.

Ecuación: $\mathrm{y}=-4,953+\left(434,3 / 1+10^{\wedge}((\log 0,9318-x))\right)$

A. Curso temporal respuesta de FBC a $1 \mu$ M ATP

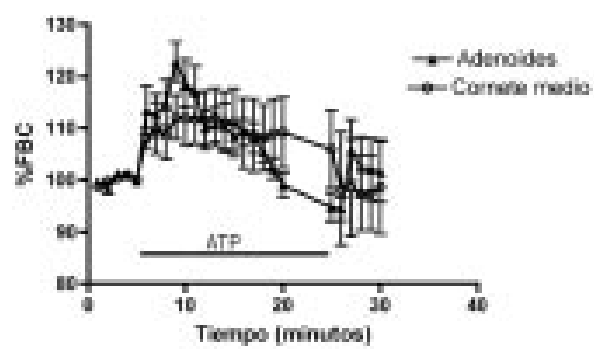

\section{B. Promedio respuesta máxima a $1 \mu M$ ATP}

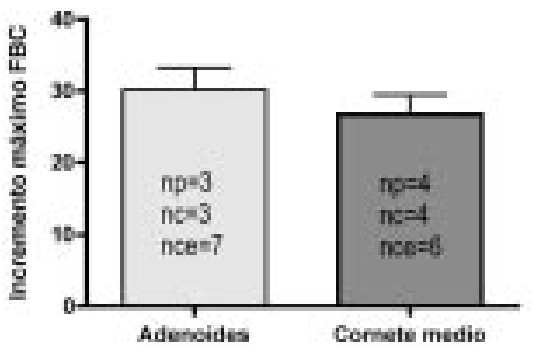

Figura 5: A. Curso temporal del efecto de 1 uM ATP sobre la FBC en cultivos primarios de células ciliadas de adenoides humanos. Luego de un período de 5 min. en la solución control (1cP), para registrar la FBC basal, se agregó $1 \mu \mathrm{M}$ de ATP y se registró la FBC durante 25 min. mediante microfotodensitometría. Los datos corresponden a los valores promedio de FBC ( un error estándar y se expresan como porcentaje respecto a la frecuencia basal o control (100\%). La línea negra indica el tiempo de exposición a ATP. B. Promedio respuesta máxima a ATP. Se graficó el promedio del incremento máximo de cada célula en respuesta a $1 \mu \mathrm{M}$ de ATP. (np: número de pacientes, nc: número de cultivos, nce: número de células medidas).

sido considerado para el tratamiento de enfermedades respiratorias, los mecanismos de liberación de ATP desde las células epiteliales no son completamente entendidos ${ }^{22-24}$. Considerando que la respuesta a ATP, estudiada y descrita en distintos modelos, es bastante sistemática, creemos que es un excelente parámetro de evaluación de respuesta ciliar en un modelo que pretenda evaluar función ciliar, y por esta razón fue el agonista escogido para validar nuestro estudio.

Las características ideales de una muestra para cultivo ciliar, teóricamente serían: origen humano, facilidad en la obtención, bajo costo, ausencia de morbilidad importante para el paciente, cantidad abundante, crecimiento rápido del cultivo, y en que se pueda reproducir las características propias del epitelio nasal in situ (interacciones celulares, señales paracrinas, etc). En nuestro estudio se realizaron biopsias de cornete medio de pacientes que serían sometidos a cirugías nasales (dacriocistorrinostomía, cirugía endoscópica de cavidades perinasales, rinoseptoplastía), porque parecía la zona más representativa y accesible de la mucosa nasal, sin embargo, en uno de estos pacientes se produjo una epistaxis que si bien fue de escasa cuantía, significó un taponamiento nasal 
por unos minutos que posteriormente cedió con el uso de oximetazolina tópica. Por el contrario, la adenoidectomía realizada en todos los pacientes incluidos en este estudio, tenía una indicación terapéutica, y por lo tanto, la obtención de la muestra no agregó morbilidad extra a la cirugía.

Al evaluar costo/efectividad de las muestras provenientes de cornete medio, con aquellas provenientes de tejido adenoídeo, se observó que las segundas presentaban actividad ciliar espontánea en menor número de días de cultivo, comparado con las de cornete medio y que además tenían subjetivamente, mayor cantidad de células ciliadas por cultivo. La explicación más lógica para este fenómeno, probablemente deriva de la mayor cantidad de muestra disponible en el caso de los adenoides, lo que permitió montar un mayor número de explantes por cultivo, y de este modo aumentar el rendimiento de la muestra. Esto ya había sido sugerido en el estudio realizado por Schuil ${ }^{25}$. A pesar que el uso de explantes de tejido adenoídeo para estudio ciliar es un método utilizado en forma recurrente en la literatura ${ }^{26-29}$, se podría cuestionar su capacidad de representar al epitelio nasal por tratarse de un epitelio con metaplasia escamosa, sin embargo este fenómeno sólo ocurre en focos, por lo que las células ciliadas remanentes son suficientes para desarrollar el cultivo.

Otra de las ventajas observadas en nuestro estudio fue la aparición junto a las células ciliadas, de células secretoras funcionalmente activas ${ }^{30}$. Creemos que la interacción entre varios tipos celulares del cultivo podría acercarnos a una mejor recreación de las condiciones existentes in vivo. El clearence mucociliar no sólo depende de la FBC, sino también de las características del mucus y del fluído periciliar ${ }^{31}$. El ATP también actúa sobre receptores purinérgicos en las células secretoras de vía aérea ${ }^{32}$, estimulando la secreción de mucus. En nuestros cultivos pudimos observar este fenómeno (dato no mostrado) y será motivo de futuras investigaciones determinar el tipo de interacción que podría existir entre secreción de mucus y FBC.

Al analizar la población de células ciliadas de los cultivos se observó que la frecuencia de batido ciliar basal no presentaba grandes variaciones dependiendo del número de días de incubación de la muestra. Esto en la práctica tiene una gran importancia. Si se hubiera establecido alguna dife- rencia en la FBC de acuerdo al período de incubación, para realizar un protocolo en que todos los cultivos fueran comparables habría sido necesario establecer un número determinado de días de cultivo, lo que habría conducido a un mayor porcentaje de cultivos perdidos por ausencia de células ciliadas (algunos demoran más días en tener actividad ciliar espontánea), o por contaminación (a mayor duración del cultivo más riesgo de contaminación). Afortunadamente al no existir esta diferencia, es posible trabajar con el cultivo cuando éste se encuentre en el mejor momento, independiente del número de días de incubación.

Dentro de un cultivo, las células ciliadas siguen una distribución normal en base a su FBC basal, es decir, se observan células con baja frecuencia y otras células con alta frecuencia. Arbitrariamente definimos que la célula más adecuada y más representativa para realizar las mediciones eran aquellas células con una frecuencia de batido ciliar basal promedio para las células de ese cultivo.

La respuesta obtenida con ATP a distintas concentraciones es comparable a la descrita por otros autores. El ATP genera un rápido incremento en la frecuencia de batido ciliar, asociado a un incremento de calcio intracelular. La respuesta máxima descrita en respuesta a ATP $10 \mu \mathrm{M}$ en cultivos de tráquea humana es de $37 \% \pm 4$ sobre la línea basal. En nuestro caso se obtuvo $27,2 \% \pm 2,7$. En células humanas la FBC se mantiene elevada después de una breve estimulación con ATP $10 \mu \mathrm{M}$ por aproximadamente 10 minutos, a pesar de que el calcio intracelular declina?.

Tampoco observamos diferencia significativa en la FBC basal ni en la respuesta a ATP entre cultivos procedentes de adenoides versus cornete medio. Considerando que macroscópica y funcionalmente ambos cultivos se comportan igual, y que los cultivos procedentes de adenoides son más costo efectivos, creemos que nuestros resultados validan el uso de éste último tejido para estudios que pueden ser extrapolados a la mucosa nasal, tal como ya lo han hecho otros autores ${ }^{25}$.

\section{CONCLUSIÓN}

El cultivo primario de células ciliadas nasales a partir de explantes de adenoides, es un modelo 
experimental reproducible, en el que es posible observar actividad ciliar y una respuesta funcional a ATP concordante con lo descrito en la literatura para otros sistemas.

En vista de lo anterior, creemos que es una excelente herramienta para desarrollar protocolos de investigación en células ciliadas humanas.

\section{Agradecimientos}

Financiamiento:

- Fondecyt 1040804 (MV), Fondos de Investigación de la Escuela de Medicina P. Universidad Católica de Chile.

- Fondos de Investigación Sociedad Chilena de Otorrinolaringología, Medicina y Cirugía de Cabeza y Cuello.

\section{BIBLIOGRAFÍA}

1. Eccles R. Anatomy and Physiology of the nose and control of nasal airflow. En: Adkinson NJ, Yunginger J, Busse W, Bochner B, Holgate S, Simons F, eds. Middleton's Allergy: Principles and Practice, $6^{\text {th }}$ ed., Mosby 2003:777.

2. Sleigh MA, Blake JR, Dormouse N. The propulsion of mucus by cilia. Am Rev Resp Dis 1988; 137: 726-41.

3. Gilain L, Zahm JM, Pierrot D, Fuchey C, Peynegre R, Puchelle E. Nasal epithelial cell culture as a tool in evaluating ciliary dysfunction. Acta Otolaryngol 1993; 113(6): 772-6.

4. Jorissen M, Willems T, Van der Schueren B. Ciliary function analysis for the diagnosis of primary ciliary dyskinesia: advantages of ciliogenesis in culture. Acta Otolaryngol 2000; 120(2): 291-5.

5. Ganbo T, Hisamatsu K, Inoue H, Mizukoshi A, Goto R, Murakami Y. The effects of leukotrienes C4 and D4 on ciliary activity of human paranasal mucous sinus in vitro. Rhinology 1995; 33(4): 199-202

6. Haxel B, Schafer D, Klimek L, Mann WJ. Prostaglandin E2 activates the ciliary beat frequency of cultured nasal human mucosa via the second messenger cyclic adenosine monophosphate. Eur Arch Otorhinolaryngol 2001; 258(5): 230-5.
7. RUNer T, LindBerg S. Effects of endothelins 1, 2 and 3 on mucosal blood flow in the upper airways. Records Otolaryngol 1996; 116(3): 457-64.

8. Devalia Jl, Sapford RJ, Rusznak C, Toumbis MJ, Davies RJ. The effects of salmeterol and salbutamol on ciliary beat frequency of cultured human bronchial epithelial cells, in vitro. Pulm Pharmacol 1992; 5(4): 257-63.

9. Centanni S, Camporesi G, Tarsia P, Guarnieri R, Allegra L. Effect of atropine on ciliary beat in human upper respiratory tract epithelial cells. Int J Tissue React 1998; 20(4): 131-6.

10. Tanaka E, Kanthakumar K, Cundell DR, Tsang KW, TAYLOR GW, KuZE F ET AL. The effect of erythromycin on Pseudomonas aeruginosa and neutrophil mediated epithelial damage. $J$ Antimicrob Chemother 1994; 33(4): 765-75

11. Zhang L, Sanderson MJ. Oscillations in ciliary beat frequency and intracellular calcium concentration in rabbit tracheal epithelial cells induced by ATP. $J$ Physiol. 2003; 546(Pt 3): 733-49.

12. Morales $B$, Barrera N, Uribe P, Mora $C$, Villalon $M$. Functional cross talk after activation of $P 2$ and $\mathrm{P} 1$ receptors in oviductal ciliated cells. $A m$ J Physiol Cell Physiol. 2000; 279(3): C658-69.

13. Lieb T, Frei CW, Frohock JI, Bookman RJ, Salathe $M$. Prolonged increase in ciliary beat frequency after short-term purinergic stimulation in human airway epithelial cells. J Physiol. 2002; 538(Pt 2): 633-46.

14. Morse DM, Smullen JL, Davis CW. Differential effects of UTP, ATP, and adenosine on ciliary activity of human nasal epithelial cells. $A m \mathrm{~J}$ Physiol Cell Physiol. 2001; 280(6): C1485-97.

15. Gayner SM, McCaffrey TV. Muscarinic ciliostimulation requires endogenous prostaglandin production. Am J Rhinol. 1998; 12(3): 203-7.

16. Schlosser RJ, Czaja JM, Yang B, McCaffrey TV. Signal transduction mechanisms in substance P-mediated ciliostimulation. Otolaryngol Head Neck Surg. 1995; 113(5): 582-8.

17. Schuil PJ, Ten Berge M, Van Gelder JM, Graamans $K$, Huizing EH. Substance $P$ and ciliary beat of human upper respiratory cilia in vitro. Ann Otol Rhinol Laryngol. 1995; 104(10 Pt 1): 798-802.

18. Verdugo P, Rumery R, Tam PY. Hormonal control of oviductal ciliary activity: effects of prostaglandins. Fertil Steril 1980; 33: 193-6. 
19. Villalón, M, Verdugo P. Control of ciliary movement in mammalian oviductal ciliated cells. Arch Biol Med Exp 1992; 24: 344-50

20. Wong LB, YeATES DB. Luminal purinergic regulatory mechanisms of tracheal ciliary beat frequency. American Journal of Respiratory Cell and Molecular Biology 1992; 7: 447-54.

21. Gheber L, Priel Z, Aflalo C, Shoshan-Barmatz V. Extracellular ATP binding proteins as potential receptors in mucociliary epithelium: characterization using [32P]3'-0-(4-benzoyl) benzoyl ATP, a photoaffinity label. Journal of Membrane Biology 1995;147: 83-93

22. LazarowskI ER, Boucher RC, Harden TK. Constitutive release of ATP and evidence for major contribution of ecto-nucleotide pyrophosphatase and nucleoside diphosphokinase to extracellular nucleotide concentrations. J Biol Chem 2000; 275: 31061-8

23. Donaldson SH, Lazarowski ER, Picher M, Knowles MR, Stutts MJ, Boucher RC. Basal nucleotide levels, release, and metabolism in normal and cystic fibrosis airways. Mol Med 2000;6: 96982.

24. Donaldson SH, Picher M, Boucher RC. Secreted and cell-associated adenylate kinase and nucleoside diphosphokinase contribute to extracellular nucleotide metabolism on human airway surfaces. Am J Respir Cell Mol Biol 2002;26: 209-15.

25. Schull PJ, Graamans K, Huizing eH. Cell suspension cultures and adenoid epithelium: an assessment of the source of material for human ciliary function experiments in vitro. Rhinology 1995; 33(2): 66-9.

26. Gayner SM, McCaffrey TV. Muscarinic ciliostimulation requires endogenous prostaglandin production. Am J Rhinol 1998; 12(3): 203-7.

27. Yang B, Schlosser RJ, McCaffrey TV. Signal transduction pathways in modulation of ciliary beat frequency by methacholine. Ann Otol Rhinol Laryngol 1997; 106(3): 230-6.

28. Schuil PJ, Ten Berge M, Van Gelder JM, Graamans K, Huizing EH. Substance P and ciliary beat of human upper respiratory cilia in vitro. Ann Otol Rhinol Laryngol 1995; 104(10 Pt 1): 798-802.

29. StaskowsKI PA, MccafFrey TV. Effect of substance $P$ on ciliary beat frequency in human adenoid explants. Otolaryngol Head Neck Surg 1992; 107(4): 553-7.

30. Espinosa M, Ríos M, González C, Villalón M. Comportamiento in Vitro de las células secretoras del epitelio respiratorio humano en respuesta a UTP. Trabajo presentado en CEPE H. Clínico P. Universidad Católica de Chile 2007.

31. Van der BaAn B. Ciliary function. Acta oto-rhinolaryngol belg 2000; 54: 293-8.

32. Kim KC, Zheng QX, Van-Seuningen I. Involvement of a signal transduction mechanism in ATPinduced mucin release from cultured airway goblet cells. Am J Respir Cell Mol Biol. 1993; 8(2): $121-5$.

Dirección: Dra. Claudia González G.

Marcoleta 352, 2 piso, Santiago.

Teléfono: 6863484. Fax: 6399645

clau_gonzalez@mac.com 